\title{
IMPORTANCE OF ENDOPHYTIC STRAINS Pantoea agglomerans IN THE BIOLOGICAL CONTROL OF Rhizoctonia solani
}

\author{
ZNACZENIE ENDOFITYCZNYCH SZCZEPÓW Pantoea agglomerans \\ W BIOLOGICZNEJ OCHRONIE PRZED Rhizoctonia solani
}

\begin{abstract}
Antagonistic activity of microorganisms against phytopathogens is mainly the results of plants' health improvement due to the inhibition of pathogens growth and the induction of plants resistance against diseases. The aim of the research was to determine antagonistic properties of Pantoea agglomerans against Rhizoctonia solani. The properties of two strains P. agglomerans BC17 and BC45 were assessed according to the following criteria: mycelial growth of $R$. solani in the presence of bacterial metabolites, an impact of P. agglomerans on the growth of sugar beet in the pots containing soil with and addition of $R$. solani and without it, the ability to produce indole-3-acetic acid (IAA). It has been recorded that antagonistic properties of tested strains are different. In the presence of metabolites of $\mathrm{BC} 17$ strains, the mycelial growth of $R$. solani was inhibited by $78 \%$ and for the strain BC45 the value amounted $46 \%$. In the pot bioassay the number of infested plants growing in the soil inoculated with $P$. agglomerans and the pathogen was lower when compared with the pots containing $R$ solani. A higher reduction of infested plants, amounting $23 \%$, was obtained for the strain BC17. Both strains had the ability to produce IAA - a plant hormone of the auxin class, in the presence of tryptophan and its absence in the medium. The highest concentration of IAA was recorded after 7 days of culturing in the supernatant obtained from the media containing $2000 \mu \mathrm{g} / \mathrm{cm}^{3}$ of tryptophan. For the strain BC17 the concentration of IAA marked in the post culturing liquid amounted $71.57 \mu \mathrm{g} / \mathrm{cm}^{3}$, and for the BC45 strain it amounted over $80 \mu \mathrm{g} / \mathrm{cm}^{3}$. Obtained results prove that $P$. agglomerans may be used in the biological protection against phytopatogenic strains of $R$. solani.
\end{abstract}

Keywords: Pantoea agglomerans, Rhizoctonia solani, auxins, antifungal activity

\section{Introduction}

In the process of plant protection against fungi, chemical fungicides containing inorganic and organic compounds are applied. Present fungicides are highly selective, active for a short time, show low toxicity to vertebrates and are easy in application and storage. Although there are strict regulations concerning fungicides which must be satisfied prior to their retail sale, laboratory and epidemiological tests have proved many of them to be harmful to people and animals. An example of such is benzimidazole (like etonitazene) and its derivatives, which play an important role in controlling fungal diseases and at the same time may affect the central nervous system in a similar way to morphine $[1,2]$.

\footnotetext{
${ }^{1}$ Chair of Biotechnology and Molecular Biology, University of Opole, ul. kard. B. Kominka 6, 45-032 Opole, Poland, phone +48 774016056

*Corresponding author: mnabrdalik@uni.opole.pl
} 
Moreover, fungicide application has a harmful effect on the environment and may be the reason for high levels of resistance showed by fungi. Fungi strains with proved resistance to fungicide are among others: Venturia inaequalis, Monilinia laxa, Botrytis spp., Neofabraea spp., Penicillium spp. and Mucor piriformis [3-5]. The application of fungicides concerns the society which pays more attention to safety and quality of the products. That is why alternative methods of biological plants protection have been searched for. When developing new biological preparations, antagonistic interactions between different microorganisms are adopted as well as antagonistic reactions between produced metabolites and the phytopathogens. The antagonistic bacteria are among others: Pseudomonas fluorescens, P. putida, P. malophilia, Agrobacterium radiobacter, Bacillus subtilis, B. cereus, B. amyloliquefaciens, B. mycoides, B. brevis, Serratia odorifera, Pantoea agglomerans [6-10]. Their mode of plant's health improvement is mainly based on the pathogen's growth inhibition and an induction of plant's resistance. However, there are a few mechanisms employed in their antagonistic activity against pathogens, which include: a competition for living space and nutrients, mycoparasite, production of antifungal compounds including antibiotics and toxins, induction of plant's resistance ISR (Induced Systemic Resistance), production of volatile compounds inhibiting pathogens' growth which may play an important role in a biocontrol process [7, 8].

The mechanism employed is very often characteristic for each strain and depends on an interaction between antagonist, pathogen and cultivated plant. A special case of antagonistic bacteria are endophytes. Endophytes are bacteria that live between living plant cells but do not cause symptoms of a disease. The close relationship established between endophytes and plants enables them to be used in the process of plant protection. Most endophytic bacteria belong to: phylum Proteobacteria genus Aeromonas, Azospirillum, Enterobacter, Erwinia, Pantoea and Pseudomonas, phylum Bacteroidetes genus Flavobacterium, phylum Actinobacteria genus Curtobacterium and Microbacterium and phylum Firmicutes genus Bacillus [8, 11-14]. They promote the growth of a host plant, stimulate biomass increase and improve plant's life span. They are also capable of nitrogen fixation, production of phytohormones (auxins, gibberellins, cytokinins, abscisic acid, jasmonic acid) and synthesis of 1-aminocyclopropane-1-carboxylic acid (ACC). They are responsible for the growth stimulation due to production of ammonia, siderophores scavenging iron, compounds inhibiting the growth of pathogens and biosurfactants. Various bacteria of Pseudomonas and Bacillus species are also able to production and grow with cyanide as the sole nitrogen source [8, 15-17].

The aim of the research was an assessment of antagonistic properties of endophytic strains of Pantoea agglomerans against Rhizoctonia solani. The possibility of using $P$. agglomerans in plant protection was determined on the basis of its antagonistic properties presented as the mycelial growth of $R$. solani and sugar beet in the presence of bacterial metabolites and the ability to produce indole-3-acetic acid (IAA) under different growing conditions (time, concentration of tryptophan).

\section{Materials and methods}

\section{Isolation and identification of endophytic bacteria}

In order to isolate endophytic bacteria the sugar beet roots were used. They were thoroughly washed and fragments of tissues for tests were cut out under aseptic conditions. Obtained samples were then rinsed with $70 \%$ propanol, shaken for 5 minutes in sodium 
hypochloride solution and rinsed three times with sterile water. In order to isolate endophytic bacterial cells, tissues were macerated in phosphate-buffered saline (PBS). The tissue homogenate was applied onto nutrient agar (NA, BioMaxima), nutrient agar with an addition of $1 \%$ saccharose (NAS, BioMaxima), nutrient agar with an addition of $0.5 \%$ yeast extract (YNA, BioMaxima), Pseudomonas agar (PsA, Biocorp), malt extract agar (MEA, Biocorp), agar with yeast extract, dextrose and calcium carbonate (YDC, BioMaxima) and agar with $2 \%$ sucrose and peptone (SPA, BioMaxima). The growing media were incubated at $25 \pm 2{ }^{\circ} \mathrm{C}$ for 48 hours. The preliminary identification of isolated mono bacterial cultures was carried out on the basis of macroscopic and microscopic description, biochemical properties and diagnostic tests ID $32 \mathrm{GN}$ and Api 20E (BioMerieux).

The isolated bacteria, recognized with tests ID 32GN and Api 20E as Pantoea, were identified as species with $16 \mathrm{~S}$ rDNA sequencing procedure. The amplification was carried out with the following primers: 20F (5'-AAGTGAAGAGTTTGATCCCTG-3') and 17R (5'-GACTTCACCCCAGTCAT-3') and with the use of Direct PCR Kits - Terra PCR Direct Polymerase Mix (Clontech, Mountain View, CA, USA = Takara Bio USA). Terra PCR Direct enables to skip DNA extraction and purification stage, and proceed directly with PCR amplification. PCR reaction was conducted in $50 \mathrm{~mm}^{3}$ capacity with $5 \mathrm{~mm}^{3}$ of template (1-day-old cultures), $25 \mathrm{~mm}^{3} 2 \mathrm{X}$ Terra PCR Direct Buffer (with $\mathrm{Mg}^{2+}, \mathrm{dNTP}$ ), 15 pmoles of forward and reverse primer mixture and $1 \mathrm{~mm}^{3}$ Terra PCR Direct Polymerase Mix $\left(1.25 \mathrm{U} / \mathrm{mm}^{3}\right)$. Cycling conditions for Terra PCR Direct included a 2 min denaturation step at $98{ }^{\circ} \mathrm{C}$ and 40 cycles of amplification at $98{ }^{\circ} \mathrm{C}$ for $10 \mathrm{~s}, 60{ }^{\circ} \mathrm{C}$ for $15 \mathrm{~s}$, and $1 \mathrm{~min}$ at $68{ }^{\circ} \mathrm{C}$. The amplified products were separated by electrophoresis with a $1 \%$ agarose gel and stained with ethidium bromide.

PCR samples were sent for sequencing at Genomed (www.genomed.pl). Sequence identity was determined with National Center for Biotechnology Information Blast (www.ncbi.nlm.nih.gov/BLAST/).

\section{Cultivation of endophytic bacteria}

Precultivation of endophytic bacteria strains was performed. Sterilized nutrient broth $\left(10 \mathrm{~cm}^{3}\right)$ in a test tube was inoculated with one loop of the strain. Then, it was incubated and shaken at $30{ }^{\circ} \mathrm{C}, 80 \mathrm{rpm}$, for 24 hours. With the use of a spectrophotometer the density of bacterial culture was measured. The samples of $2.0\left(10^{6} \mathrm{CFU} / \mathrm{cm}^{3}\right)$ density were then added to $100 \mathrm{~cm}^{3}$-Erlenmeyer flask containing $50 \mathrm{~cm}^{3}$ of sterile broth. Erlenmeyer flask was kept in an incubator at $30^{\circ} \mathrm{C}$ with $80 \mathrm{rpm}$ for 48 hours. The cultures were centrifuged at $10000 \mathrm{rpm}$ for 20 minutes and obtained supernatant (cell-free culture) was used for the further tests.

\section{Cultivation of Rhizoctonia solani}

The inoculum of $R$. solani, which was used to infest the soil, was grown on a sand-maize medium with sterile sand and an addition of $3 \%$ cornmeal. The containers of $1 \mathrm{dm}^{3}$ capacity were filled up to half of their volume with the medium and sterilized. The medium was inoculated with discs of 1-cm-diameter with 1-week old mycelium grown on a PDA medium. The content of the containers was stirred and left for incubation, for three weeks. The containers were shaken every few days, and moistened when necessary. 


\section{Detection and assay of antagonistic properties of endophytic bacteria strains}

Culture-plate method. In the research the antagonistic properties of endophytic strains $P$. agglomerans against the phytopathogenic strain $R$. solani ID105 qualified to anastomosis group AG 2-2 IIIB were determined. In the control trials, cell-free culture obtained after 48 hours of culturing $P$. agglomerans was added to PDA medium (BioMaxima). The medium was then inoculated with 8-mm agar discs with 7-day old mycelium of $R$. solani ID105. The control trial contained $R$. solani cultures and broth instead of cell-free culture. The culturing was incubated at $22{ }^{\circ} \mathrm{C}$. The diameter of discs was measured every day until the mycelium in a control trial covered the whole plate and reached the edge of it. The tests were run in three replications, i.e. one plate with the medium and the mycelial disc constituted on replication. The effect of endophytic strains $P$. agglomerans on the growth of $R$. solani was calculated according to the formula below [9]:

$$
I R G=\frac{A}{D}+\frac{b_{1}}{d_{1}}+\frac{b_{2}}{d_{2}}+\cdots+\frac{b_{x}}{d_{x}}
$$

where $I R G$ represents the growth rate index, $A$ is a mean value of diameter measurements [mm], $D$ is the length of the experiment (number of days), $b_{1}, b_{2}, b_{x}$ denote an increase in a diameter size since the last measurement and $d_{1}, d_{2}, d_{x}$ are the number of days since the last measurement.

Effect of endophytic bacteria strains on the growth of sugar beet. An impact of $P$. agglomerans strains on the growth of sugar beet was tested in a pot bioassay, in which pots were filled with both uninfested soil and soil with $R$. solani. For the experiment garden soil and field soil were used and mixed with perlite in the proportion $2: 1: 0.5$. In each $500 \mathrm{~cm}^{3}$ pot 10 pelleted seeds of sugar beet (variety Natura) were sown. The plants were grown in a fluorine-type light for 12 hours at $22{ }^{\circ} \mathrm{C}$. The pots were watered with tap water in order to keep the soil moistened and all infested plants with dying hypocotyls were regularly removed during the experiment. After 6 weeks, the weakest plants were removed and $5 \mathrm{~cm}^{3}$ of 2-day-old cultures of P. agglomerans $\mathrm{BC} 17$ and P. agglomerans $\mathrm{BC} 45$ were added. After one week, additional $5 \mathrm{~cm}^{3}$ of $R$. solani 2-2 III B (AG) obtained from 3-week old cultures grown on the sand-maize medium were added to part of the pots.

The degree of root infestation was evaluated according to a 4-degree scale as follows: 0 - no disease symptoms, 1 - low infection (only single small spots), 2 - high infection (50\% or more of the root surface damaged and rotted), 3 - dead plant with completely damaged root [18]. The percentage of infested plants was calculated and then the index of the disease roots was calculated according to Townsend-Heuberger formula [19]:

$$
I D=\frac{\sum(a \cdot n) \cdot 100 \%}{N \cdot 3}
$$

where: $I D$ - index of the disease roots [\%], $a$ - degree of infection according to the scale $0-3, n$ - number of roots per category, $N$ - total number of roots screened, 3 - highest degree of infection.

Healthy plants had the length of the roots and leaves measured. Also the fresh and dry weight was determined. The measured values were calculated per single plant. 


\section{IAA production characteristic}

To determine the amounts of IAA produced by endophytic bacteria strains, a colorimetric technique was applied with Salkowski reagent [20].

The isolates of $P$. agglomerans were grown in LB medium (Laurin Broth) supplemented with L-tryptophan at concentrations of 500, $1000,2000 \mu \mathrm{g} / \mathrm{cm}^{3}$ and incubated at $30{ }^{\circ} \mathrm{C}$ for 7 days. In the control trials the bacterial cultures were growth in medium without L-tryptophan. The production of IAA was measured after every 24 hours. After the incubation, the medium was centrifuged for 20 minutes at $10,000 \mathrm{rpm}$ at $10{ }^{\circ} \mathrm{C}$. Supernatant was reserved and $1 \mathrm{~cm}^{3}$ was mixed with $2 \mathrm{~cm}^{3}$ of Salkowski reagent and kept in the dark. The optical density (OD) was recorded at $530 \mathrm{~nm}$ after 30 minutes.

\section{Statistical analysis}

Statistical significance was determined using an analysis of variance (ANOVA) followed by Tukey's HSD test. Values were considered significantly different at $p<0.05$. The statistical calculations were done with Miscrosoft Excel spreadsheet.

Having completed the calculations, the assessment of the distribution of the remained of the set after model construction was conducted and presented with histograms. It has been stated that the distribution may be considered for unimodal and quite symmetrical in reference to the modal value. It has been concluded that the application of ANOVA method and Tukey's HSD test for the analysis of obtained results was justified. However, the figures have not been presented in the paper as they would constitute the major part of it and at the same time would not contribute to reaching the final conclusion.

\section{Results and discussion}

The media applied in the research allowed to isolate the strains from the sugar beet root, which on most of them grew as yellow colonies. On the media supplemented with sucrose (NAS, SPA) and PsA abundant growth was observed of the colonies which were shiny, convex, very mucous and sticky. On the media with yeast extract (NA, YNA, YDC) the colonies were much smaller, shiny but smooth on the surface. The growth on the MEA and YDC medium was noted only after 2-3 days later than on other media.

The selected isolates were described as asporogenous, moveable Gramm-negative rods of the size $0.6-0.9 \times 1.0-1.5 \mu \mathrm{m}$. The preliminary identification performed with tests ID $32 \mathrm{GN}$ and Api 20E determined biochemical properties of bacteria and thus classify them as Pantoea. In run tests, the strains did not produce oxidase, hydrogen sulfide, urease nor indole. However, they melted gelatin, reacted positively in VP test, reduced the nitrate. The strains selected in the research used different sugars as the only source of nutrients: glucose, mannose, rhamnose, sucrose and arabinose. The following were not used as nutrients: sorbitol, fucose, glycogen, melibiose nor citrate. The strains fermented glucose to acids under anaerobic conditions. Noted differences between strains resulted from their abilities to use sodium acetate.

Tested strains were identified as $P$. agglomerans on the basis of the results obtained in $16 \mathrm{~S}$ rDNA gene sequence analysis which were compared with NCBI database. The almost complete $16 \mathrm{~S}$ rDNA gene was sequenced and the (1500 bp) analysis clearly demonstrated that strains BC17 and BC45 were members of the genus Pantoea and exhibited maximum similarity with the $16 \mathrm{~S}$ rDNA sequence of Pantoea agglomerans. Two strains of P. agglomerans isolated from selected sugar beet roots were marked as BC17 and BC45. 
Conducted tests showed the direct effect of the metabolites produced by $P$. agglomerans strains $\mathrm{BC} 17$ and $\mathrm{BC} 45$ on the growth pace of $R$. solani strain ID105 reflected by calculated values of the mycelial growth rate index $(I R G)$ and an inhibition of the mycelial growth (Table 1). The isolated strain $R$. solani ID105 had a fast growth rate and within 5 days it overgrew the medium completely. An average daily growth rate of the mycelium amounted $16.4 \mathrm{~mm}$. In the presence of $P$. agglomerans strains $\mathrm{BC} 17$ and $\mathrm{BC} 45$ the growth rate of the phytopathogen decreased and the average daily growth rate amounted 3.43 and $8.97 \mathrm{~mm}$ respectively. The isolated strains used in the experiment were highly antagonistic towards the mycelium of $R$. solani and reduced the $I R G$ by $78 \%$ for the BC17 strain and by $46 \%$ for the BC45 (Table 1 ).

Table 1

Inhibition of Rhizoctonia solani mycelial growth on potato dextrose agar by Pantoea agglomerans strains

\begin{tabular}{|c|c|c|c|c|}
\hline & \multicolumn{2}{|c|}{$\boldsymbol{I R G}[-]$} & \multicolumn{2}{c|}{ Reduction of the mycelial growth [\%] } \\
\cline { 2 - 5 } & mean & $\boldsymbol{S D}^{*}$ & mean & - \\
\hline $\begin{array}{c}\text { Control trial } \\
\text {. solani } \text { ID105 }\end{array}$ & $92.56 \mathrm{a}$ & \pm 0.21 & - & \pm 2.26 \\
\hline $\begin{array}{c}\text { R. solani ID105 + } \\
\text { P. agglomerans BC17 }\end{array}$ & $20.31 \mathrm{~b}$ & \pm 2.13 & 72.04 & \pm 10.2 \\
\hline $\begin{array}{c}\text { R. solani ID105 + } \\
\text { P. agglomerans BC45 }\end{array}$ & $49.92 \mathrm{c}$ & \pm 9.65 & 41.3 & \\
\hline
\end{tabular}

* standard deviation, diffecrent letters indicate significant differences (ANOVA, $p<0.05$, Tukey's HSD test)

The biological control of plants pathogens employs endophytic bacteria, among which Bacillus and Pseudomonas are most frequently tested groups [8, 15, 21-25]. Also stains of Pantoea take part in the process, however, no research has been conducted on their antagonistic properties against $R$. solani belonging to anastomosis group AG 2-2, which causes root and crown rot in sugar beets. Among few research papers concerning biological methods for plants protection against $R$. solani, there is one written by Barnett el al. [26] in which the authors evaluated the influence of rhizosphere bacteria, including $P$. agglomerans, on $R$. solani AG 8 a major wheat root pathogen. It should be noted, however, that Rhizoctonia is a genetically varied group and fungi of this group have some degree of host specificity and cause disease on different plants. For example, the strains of anastomosis group which cause wheat diseases are the same ones that induce damping-off in sugar beet seedlings (AG 4) but differ from strains inducing root rot in sugar beets (AG 2-2) [27]. Therefore, it is crucial to identify both the anastomosis group and the plant.

Pantoea strains were used in post-harvest biological control of fungi in fruits and citrus, inhibiting the growth of fungi such as Penicillium expansum [28-30], P. digitatum [31-33], P. italicum [31], Botrytis cinerea [28, 29], Monilinia laxa and Rhizopus stolonifer $[29,34]$. They also limited the growth of Macrophomina phaseolina, a causal agent of charcoal rot of soybean [35] as well as Stenocarpella maydis and S. macrospora, causing ear rot in corn [36]. The above mentioned research papers showed that Pantoea strains inhibited the growth of pathogens to a different degree depending on the following parameters: the growth phase, enzymatic activity, ability to produce metabolites, density of inoculum.

The culture-plate method employed in the research was taken as preliminary screening criteria for selecting the antagonistic properties of tested strains. In the research PDA medium was used, so competition might be excluded as a mode of action for the antifungal 
isolates according to Lee et al. [37]. In the research, the inhibition of the $R$. solani growth by the antagonistic bacteria occurred at $48 \mathrm{~h}$ probably due to the late production of antifungal metabolites. Tested strains inhibited the growth of the pathogen to a different degree, which suggests that the mode of action exerted or the type of antifungal metabolites produced by the isolates may vary from each other. Moreover, there was no physical contact between isolates and the phytopathogen suggesting that the endophytic Pantoea species could produce specific antifungal exocellular metabolites which inhibit the growth of the mycelia.

Conducted pot bioassay allowed to estimate the influence of tested bacteria on the infection of the sugar beet by $R$. solani (Tables 2 and 3). No infested plants were noted in the control trials. When $R$. solani ID105 was introduced into the soil, the number of infested plants increased up to $83.75 \%$. The dominant group of infested plants had roots rated on the scale as 3 and the value of $I D$ amounted $62 \%$. In the pots with the soil containing strains $P$. agglomerans $\mathrm{BC} 17$ and $\mathrm{BC} 45$ single plants with infected roots (1 on the scale) were observed and their number amounted 5.0 and $4.17 \%$ respectively. The differences between the above trials and the control were statistically insignificant. In case of healthy plants (assessed as 0 on the scale), an addition of tested strains to the soil did not affect the following parameters: the length of root and leaf, dry and fresh weight of a single plant. However, when both the pathogen and the endophyte were introduced into the soil, the significant differences concerning the degree of plant infection were noted for $P$. agglomerans $\mathrm{BC} 17$ strain. The difference in the number of infested plants in comparison with the number of plants infested by only $R$. solani ID105, decreased by over $23 \%$ while for the strain $P$. agglomerans BC45 the differences were statistically insignificant and amounted only $7.5 \%$. The statistically significant influence of P. agglomerans BC45 with $R$. solani ID105 has been noted when analysing the fresh and dry weight of the plants and no such influence has been noted on the length of the root and the leaf.

Table 2

Effect of Pantoea agglomerans $\mathrm{BC} 17$ on the growth of sugar beet

\begin{tabular}{|c|c|c|c|c|c|c|}
\hline \multirow[b]{2}{*}{ Parameter } & \multirow[b]{2}{*}{$I D[\%]$} & \multirow[b]{2}{*}{$\begin{array}{l}\text { Number } \\
\text { of infested } \\
\text { roots [\%] }\end{array}$} & \multicolumn{4}{|c|}{ Characteristic of healthy plants } \\
\hline & & & $\begin{array}{c}\text { Root length } \\
{[\mathrm{cm}]}\end{array}$ & $\begin{array}{l}\text { Leaf length } \\
{[\mathrm{cm}]}\end{array}$ & $\begin{array}{c}\text { Fresh } \\
\text { weight } \\
\text { [g/plant] }\end{array}$ & $\begin{array}{l}\text { Dry weight } \\
\text { [g/plant] }\end{array}$ \\
\hline Control trial & $0 \mathrm{a}$ & $0 \mathrm{a}$ & $9.03 \mathrm{a}$ & $17.4 \mathrm{a}$ & $5.85 \mathrm{a}$ & $0.64 \mathrm{a}$ \\
\hline R. solani ID105 & $62.08 \mathrm{~b}$ & $83.75 \mathrm{~b}$ & $9.83 \mathrm{a}$ & $16.0 \mathrm{a}$ & $4.28 \mathrm{a}$ & $0.46 \mathrm{a}$ \\
\hline P. agglomerans $\mathrm{BC} 17$ & $1.39 \mathrm{a}$ & $5.0 \mathrm{a}$ & $10.85 \mathrm{a}$ & $17.04 \mathrm{a}$ & $4.52 \mathrm{a}$ & $0.38 \mathrm{a}$ \\
\hline $\begin{array}{l}\text { P. agglomerans } \mathrm{BC} 17+ \\
\text { R. solani } \mathrm{ID} 105\end{array}$ & $43.52 \mathrm{c}$ & $60.42 \mathrm{c}$ & $11.76 \mathrm{a}$ & $16.43 \mathrm{a}$ & $4.64 \mathrm{a}$ & $0.38 \mathrm{a}$ \\
\hline
\end{tabular}

Different letters indicate significant differences (ANOVA, $p<0.05$, Tukey's HSD test)

Suppression of Rhizoctonia diseases is due to the contribution of multiple groups of interacting organisms. Barnett et al. [26] using wheat-soil-pathogen bioassays concluded that the main factor inhibiting the growth of $R$. solani is an interaction of 3 phylogenetically diverse groups of bacteria $P$. agglomerans, Exiguobacterium acetylicum, and Microbacteria. The disease was suppressed in soils with only one of the strains and with the combination of the three of them. However, co-inoculation with all three groups produced a consistently higher degree of disease inhibition (35\%) than inoculation with a single group or pairs of groups. The interaction between the 3 bacterial groups allowed to suppress 
the root infection up to $35 \%$. The authors stress that the bacterial combination did not reduce the amount of pathogen's DNA in the soil but suppress the root disease symptoms. Root associated $P$. agglomerans promoted the growth of infected wheat plants. Walpola and Yoon [38] in the research concerning the influence of $P$. agglomerans strain PBS-1 and Burkholderia anthina strain PBS-2 on the growth of tomato plants noted an increase in the plant height, root length, and dry weight of shoot and root when compared to non-inoculated tomato plants. The same authors confirm more beneficial results when the soil is inoculated with both strains than when it is inoculated with single strains.

Table 3

Effect of Pantoea agglomerans BC45 on the growth of sugar beet

\begin{tabular}{|c|c|c|c|c|c|c|}
\hline \multirow[b]{2}{*}{ Parameter } & \multirow[b]{2}{*}{$I D[\%]$} & \multirow[b]{2}{*}{$\begin{array}{c}\text { Number } \\
\text { of infested } \\
\text { plants }[\%]\end{array}$} & \multicolumn{4}{|c|}{ Characteristic of healthy plants } \\
\hline & & & $\begin{array}{c}\text { Root length } \\
{[\mathrm{cm}]}\end{array}$ & $\begin{array}{c}\text { Leaf length } \\
{[\mathrm{cm}]}\end{array}$ & $\begin{array}{c}\text { Fresh } \\
\text { weight } \\
\text { [g/plant] }\end{array}$ & $\begin{array}{c}\text { Dry weight } \\
\text { [g/plant] }\end{array}$ \\
\hline Control trial & $0 \mathrm{a}$ & $0 \mathrm{a}$ & $9.03 \mathrm{a}$ & $17.4 \mathrm{a}$ & $5.85 \mathrm{a}$ & $0.64 \mathrm{a}$ \\
\hline R. solani $\mathrm{ID} 105$ & $62.08 \mathrm{~b}$ & $83.75 \mathrm{~b}$ & $9.83 \mathrm{a}$ & $16.0 \mathrm{a}$ & $4.28 \mathrm{a}$ & $0.46 \mathrm{a}$ \\
\hline P. agglomerans $\mathrm{BC} 45$ & $1.39 \mathrm{a}$ & $4.17 \mathrm{a}$ & $10.74 \mathrm{a}$ & $17.02 \mathrm{a}$ & $4.85 \mathrm{a}$ & $0.41 \mathrm{a}$ \\
\hline $\begin{array}{c}\text { P. agglomerans } \mathrm{BC} 45+ \\
\text { R. solani } \mathrm{ID} 105\end{array}$ & $61.25 \mathrm{~b}$ & $76.25 \mathrm{~b}$ & $10.17 \mathrm{a}$ & $16.5 \mathrm{a}$ & $3.05 \mathrm{~b}$ & $0.19 \mathrm{~b}$ \\
\hline
\end{tabular}

Different letters indicate significant differences (ANOVA, $p<0.05$, Tukey's HSD test)

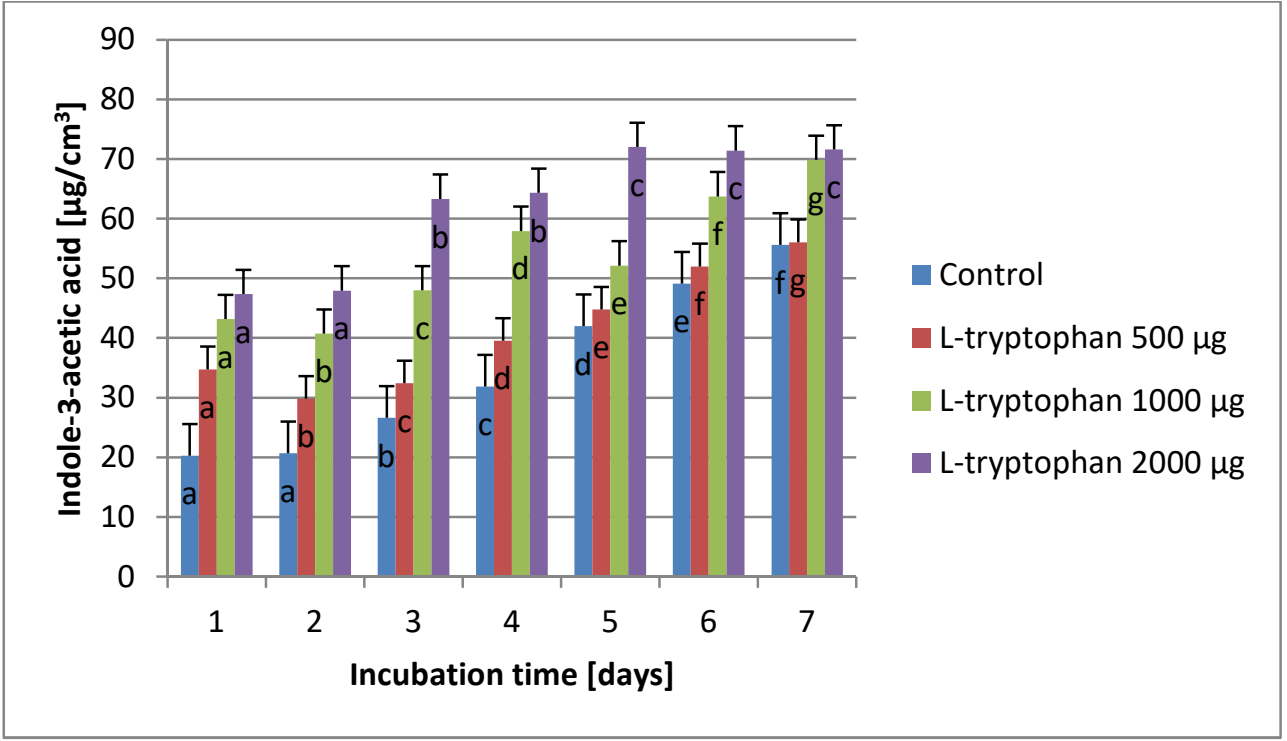

Fig. 1. Effect of L-tryptophan on IAA production by P. agglomerans BC17. Different letters indicate significant differences (ANOVA, $p<0.05$, Tukey's HSD test)

In the research, it has been determined how the concentration of L-tryptophan and the time affect the process of biosynthesis of IAA by strains $P$. agglomerans. The strains of $P$. agglomerans $\mathrm{BC} 17$ and $\mathrm{BC} 45$ under study produced IAA in a different amount in the presence of L-tryptophan and in its absence. The relationship between the reaction of IAA 
biosynthesis and the dose of L-tryptophan and the reaction time was proportional. It has been recorded that with the increase in the L-tryptophan concentration and the time of reaction, the amount of produced IAA also increased. For the strain P. agglomerans BC17 the lowest amount of IAA $20.26 \mu \mathrm{g} / \mathrm{cm}^{3}$ was obtained in the absence of L-tryptophan after one day of incubation. The maximum production of IAA $71.57 \mu \mathrm{g} / \mathrm{cm}^{3}$ was achieved when medium was supplemented with $2000 \mu \mathrm{g} / \mathrm{cm}^{3}$ concentration of L-tryptophan as a precursor after 7 days (Fig. 1). Similar results were noted in case of the strain P. agglomerans BC45, for which the lowest concentration of IAA $15.04 \mu \mathrm{g} / \mathrm{cm}^{3}$ was obtained on the first day on the medium without amino acid and the highest concentration amounting about $80 \mu \mathrm{g} / \mathrm{cm}^{3}$ occurred after 3 days in the presence of the highest concentration of L-tryptophan. On the following days, the amount was similar and the differences between consecutive results were statistically insignificant (Fig. 2).

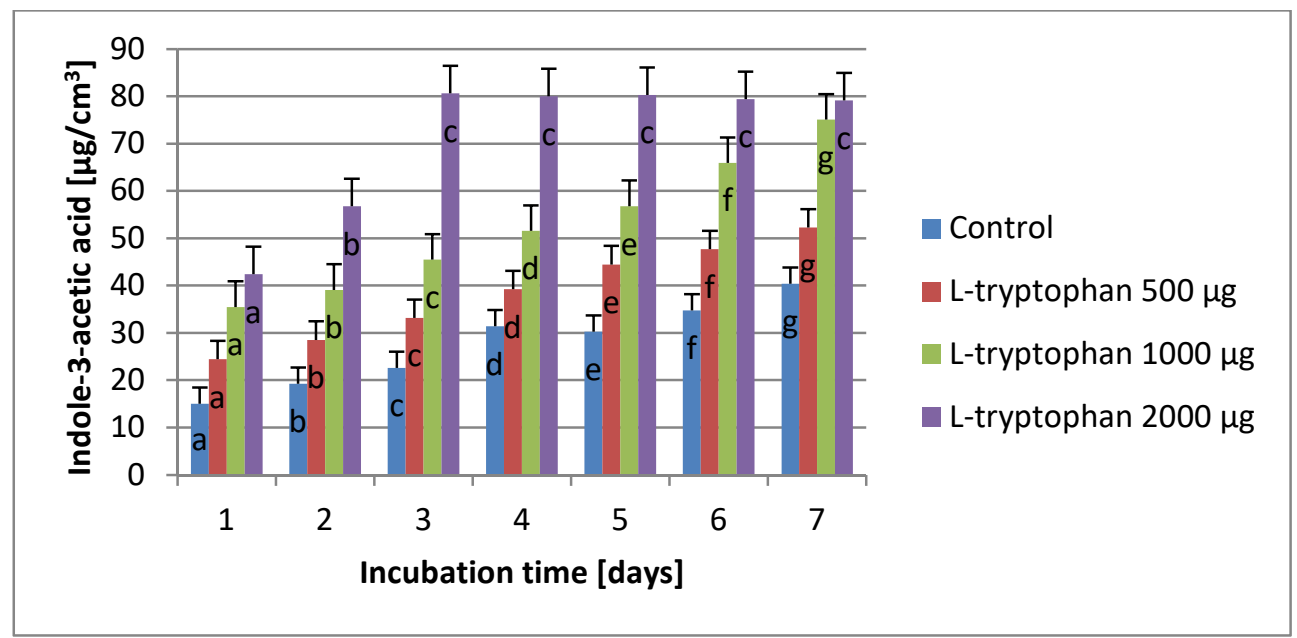

Fig. 2. Effect of L-tryptophan on IAA production by $P$. agglomerans BC45. Different letters indicate significant differences (ANOVA, $p<0.05$, Tukey's HSD test)

In order to determine the abilities to produce IAA by tested strains $P$. agglomerans $\mathrm{BC} 17$ and $\mathrm{BC} 45$, the optimal conditions for bacterial growth was provided, that is $30{ }^{\circ} \mathrm{C}$ and $\mathrm{pH} \mathrm{7,} \mathrm{which} \mathrm{was} \mathrm{confirmed} \mathrm{by} \mathrm{Apine} \mathrm{and} \mathrm{Jadhav} \mathrm{[39]} \mathrm{in} \mathrm{their} \mathrm{research} \mathrm{on} \mathrm{the}$ optimization of biosynthesis of IAA by P. agglomerans strain PVM. Under the same conditions, the authors obtained maximum amount of IAA $1530 \mu \mathrm{g} / \mathrm{cm}^{3}$ at $30{ }^{\circ} \mathrm{C}$ and maximum amount of IAA $1441 \mu \mathrm{g} / \mathrm{cm}^{3}$ at $\mathrm{pH}$ 7. The same was proved by Dastager et al. [14] who pointed that the most favourable conditions for IAA biosynthesis by the strains Pantoea NII-186 was $28{ }^{\circ} \mathrm{C}$. Under these conditions the isolate was able to produce $59 \mu \mathrm{g} / \mathrm{cm}^{3}$ of IAA. Apine and Jadhav [39] also analysed the effect of incubation time to optimize culturing conditions. The production of IAA was directly proportional to the incubation time and after 2 days of incubation IAA production enhanced by twofold, while in authors' own research presented in this paper, the amount of produced IAA doubled only after 7 days of incubation. Apine and Jadhav [39] obtained much higher concentrations of IAA. However, an inversed relationship was observed in this case, as with the increase in L-tryptophan concentration in the medium, the amount of determined IAA decreased. 
P. agglomerans strain PVM produced the highest amount of IAA measuring $1.577 \mu \mathrm{g} / \mathrm{cm}^{3}$ on the medium supplemented with L-tryptophan at concentration $1000 \mu \mathrm{g} / \mathrm{cm}^{3}$, whereas at concentration $2000 \mu \mathrm{g} / \mathrm{cm}^{3}$ the amount of IAA decreased twofold (about $800 \mu \mathrm{g} / \mathrm{cm}^{3}$ ). Different results presented Walpola and Yoon [38], who analysed the ability to synthesize IAA by $P$. agglomerans PBS-1 and $B$. anthina PBS-2 and recorded the concentrations of 10 and $7.5 \mu \mathrm{g} / \mathrm{cm}^{3}$ respectively. However, the authors applied low concentration of L-tryptophan in the medium amounting $20 \mu \mathrm{g} / \mathrm{cm}^{3}$. Moreover, in the studies of Walpola and Yoon [38] it has been observed that the ability to synthesize IAA was decreasing with the incubation time. Cimmino et al. [40] analysed 5 strains of $P$. agglomerans which produced low amount of IAA in the range of 5.4 to $13.2 \mu \mathrm{g} / \mathrm{cm}^{3}$ in the presence of $500 \mu \mathrm{g} / \mathrm{cm}^{3}$ of L-tryptophan in the medium after 4 days of incubation. Also in the research of Sergeeva et al. [41] all of six isolates $P$. agglomerans produced IAA when L-tryptophan was present in the culturing medium. The concentrations of produced IAA increased with increasing concentrations of L-tryptophan, reaching a maximum at $250 \mu \mathrm{g} / \mathrm{cm}^{3}$ for isolates 2-54, 3-117, 5-105 and GR12-2, and at $500 \mu \mathrm{g} / \mathrm{cm}^{3}$ for isolates 2-32, 4-20 and 5-51. At lower concentrations of L-tryptophan, the production of IAA was at a very low level. Presented results of the research on the biosynthesis of IAA by different strains of $P$. agglomerans allow to conclude that the concentration of L-tryptophan as a precursor of IAA should range between 250 to $1000 \mu \mathrm{g} / \mathrm{cm}^{3}$ and the incubation time of the growing medium should not be shorter than 2 days. The comparison of obtained results with the pot bioassay proved that the higher amount of IAA the strain produced in the medium with no precursor (L-tryptophan) the better effect it had on the growth of infected plants.

\section{Conclusions}

Conducted research confirms antifungal activity of different strains $P$. agglomerans and therefore proves they could be an alternative to chemical fungicides. Tested strains suppressed the disease induced by $R$. solani to a different degree which might be the result of their ability to produce IAA. The strain P. agglomerans $\mathrm{BC} 17$ produced much more auxins on the medium with no addition of tryptophan in comparison with the strain BC45. These bacteria were associated with the suppression of root disease caused by $R$. solani but did not reduce pathogen levels in the soil. The analysis of reference research papers indicated that soil disease suppression cannot simply be ascribed to a single microbial group and may involve more biocontrol bacteria than previously reported or may even be the synergistic effect of many microbial groups. Therefore, future research will concern the ability to reduce the growth of the sugar beet pathogens with endophytic strains.

\section{References}

[1] Gomez TH, Meisch RA. Pharmacol, Biochem Behavior. 2004;79:261-267. DOI: 10.1016/j.pbb.2004.07.005.

[2] Wightwick A, Walters R, Allinson G, Reichman S, Menzies N. Environmental Risks of Fungicides Used in Horticultural Production Systems. In: Carisse O, editor. Fungicides. Rijeka: InTech; 2010. DOI: $10.5772 / 13032$.

[3] Broniarek-Niemiec A. Prog Plant Prot. 2016;56(1):52-61. DOI: 10.14199/ppp-2016-009.

[4] Egüen B., Melgarejo P, De Cal A. Eur J Plant Pathol. 2016;145:815-827. DOI:10.1007/s10658-016-0871-4.

[5] Brent KJ, Hollomon DW. Fungicide Resistance in Crop Pathogens: How Can It Be Managed? FRAC Monograph $1 \quad 2^{\text {nd }}$ ed.). Brussels: Fungicide Resistance Action Committee; 2007. http://www.frac.info/docs/default-source/publications/monographs/monograph-1.pdf

[6] Sakalauskas S, Kačergius A, Janušauskaitė D, Čitavičius D. Žemdirbystè - Agriculture. 2014;101(2):185-192. DOI: 10.13080/z-a.2014.101.024. 
Importance of endophytic strains Pantoea agglomerans in the biological control of Rhizoctonia solani 341

[7] Deveau A, Gross H, Palin B, Mehnaz S, Schnepf M, Leblond P, et al. FEMS Microbiol Ecol. 2016;92(8):1-11. DOI: 10.1093/femsec/fiw107.

[8] Choudhary DK, Prakash A, Johri BN. Indian J Microbiol. 2007;47(4):289-297. DOI: 10.1007/s12088-007-0054-2.

[9] Nabrdalik M, Grata K. Proc ECOpole. 2014;8(1):65-69. DOI: 10.2429/proc.2014.8(1)008.

[10] Nagrodzka K, Moliszewska E, Grata K, Nabrdalik M. Proc ECOpole. 2016;10(2):741-748. DOI: 10.2429/proc.2016.10(1)081.

[11] Santoyo G, Moreno-Hagelsieb G, Orozco-Mosqueda MDC, Glick BR. Microbiol Res. 2016;183:92-99. DOI: 10.1016/j.micres.2015.11.008.

[12] Brader G, Compant S, Mitter B, Trognitz F, Sessitsch A. Curr Opin Biotech. 2014;27:30-37. DOI: 10.1016/j.copbio.2013.09.012.

[13] Mishra A, Chauhan PS, Chaudhry V, Tripathi M, Nautiyal CS. Antonie Van Leeuwenhoek. 2011;100(3):405-413. DOI: 10.1007/s10482-011-9596-8.

[14] Dastager SG, Deepa CK, Puneet SC, Nautiyal CS, Pandey A. Lett Appl Microbiol. 2009;49(1):20-5. DOI: 10.1111/j.1472-765X.2009.02616.x.

[15] Saraf M, Pandya U, Thakkar A. Microbiol Res. 2014;169:18-29. DOI: 10.1016/j.micres.2013.08.009.

[16] Ma Y, Oliveira RS, Freitas H, Zhang C. Front Plant Sci. 2016;7:1-19. DOI: 10.3389/fpls.2016.00918.

[17] Karimi AM, Soroor S, Farhad S. Ecol Chem Eng S. 2017;24(3):371-379. DOI:10.1515/eces-2017-0024.

[18] Moliszewska EB. Etiologia wybranych chorób korzeni buraka cukrowego. (The etiology of selected diseases of sugar beet roots). Studies and Monographs 412. Opole: University of Opole; 2009. ISBN: 9788373953291.

[19] Konno M, Iwamoto S, Seiwa K. J Ecol. 2011;99: 1394-1401. DOI: 10.1111/j.1365-2745.2011.01869.x

[20] Szkop M, Sikora P, Orzechowski S. Folia Microbiol (Praha). 2012;57(1):1-4. DOI: 10.1007/s12223-011-0089-y

[21] Ghai S, Sood SS, Jain RK. Indian J Microbiol. 2007;47:77-80. DOI: 10.1007/s12088-007-0014-x.

[22] Kai M, Effmert U, Berg G, Piechulla B. Arch Microbiol. 2007;187(5):351-360. DOI: 10.1007/s00203-006-0199-0.

[23] Imran H, Darine TH, Mohamed ELG. Afr J Biotechnol. 2012;11(81):14660-14670. DOI: 10.5897/AJB10.2508.

[24] Lahlali R, Bajii M, Jijakli MH. Commun Agric Appl Biol Sci. 2007;72(4):973-982. http://hdl.handle.net/2268/36847.

[25] Yin C, Hulbert SH, Schroeder KL, Mavrodi O, Mavrodi D, Dhingra A, et al. Appl Environ Microbiol. 2013;79(23):7428-7438. DOI: 10.1128/AEM.01610-13.

[26] Barnett SJ, Roget DK, Ryder MH. Aust J Soil Res. 2006;44:331-342. DOI: 10.1071/SR05113.

[27] Harveson RM. Identifying and distinguishing seedling and root rot diseases of sugar beets. Plant Health Progress. 2006. DOI: 10.1094/PHP-2006-0915-01-DG.

[28] Nunes C, Teixido N, Usall J, Vinas I. Acta Hort. 2001;553(2):403-404. DOI: 10.17660/ActaHortic.2001.553.92.

[29] Nunes C, Usall J, Teixidó N, Fons E, Vinas I. J Appl Microbiol. 2002;92(2):247-55. DOI: 10.1046/j.1365-2672.2002.01524.x.

[30] Morales H, Sanchis V, Usall J, Ramos AJ, Marín S. Int J Food Microbiol. 2008;122(1-2):61-67. DOI: 10.1016/j.ijfoodmicro.2007.11.056.

[31] Teixidó N, Usall J, Palou L, Asensio A, Nunes C, Vinas I. Eur J Plant Pathol. 2001;107:685-694. DOI:10.1023/A:1011962121067.

[32] Zamani M, Sharifi Tehrani A, Ahmadzadeh M, Hosseininaveh V, Mostofy Y. J Plant Pathol. 2009;91(2):437-442. DOI: 10.4454/jpp.v91i2.975.

[33] Plaza P, Usall J, Smilanick JL, Lamarca N, Vinas I. J Food Prot. 2004;67(4):781-786. DOI: 10.4315/0362-028X-67.4.781.

[34] Bonaterra A, Mari M, Casalini L, Montesinos E. Int J Food Microbiol. 2003;84(1):93-104. DOI: 10.1016/S0168-1605(02)00403-8.

[35] Vasebi Y, Alizadeh A, Safaie N. J Crop Prot. 2015;4(1):43-57. http://jcp.modares.ac.ir/article_11365_b8e009695849033e6cbf57a5470e8a5f.pdf.

[36] Petatán-Sagahón I, Anducho-Reyes MA, Silva-Rojas HV, Arana-Cuenca A, Tellez-Jurado A, Cárdenas-Álvarez IO, et al. Int J Mol Sci. 2011;12(9):5522-5537. DOI: 10.3390/ijms12095522.

[37] Lee KJ, Kamala-Kannan S, Sub HS, Seong CK, Lee GW. World J Microbiol Biotechnol. 2008;24:1139-1145. DOI:10.1007/s11274-007-9585-2.

[38] Walpola BH, Yoon MH. Afr J Microbiol Res.2013;7(3):266-275. DOI: 10.5897/AJMR12.2282.

[39] Apine OA, Jadhav JP. J Appl Microbiol. 2011;110(5):1235-1244. DOI:10.1111/j.1365-2672.2011.04976.x. 
[40] Cimmino A, Andolfi A, Marchi G, Surico G, Evidente A. Phytopathol Mediterr. 2006;45:247-252. DOI: 10.14601/Phytopathol_Mediterr-1831.

[41] Sergeeva E, Hirkala DLM, Nelson LM. Plant Soil. 2007;297(1):1-13. DOI: 10.1007/s11104-007-9314-5. 